\title{
RESEARCH
}

Open Access

\section{Deposition means storage and not loss}

\author{
Rainer Schenk ${ }^{1,2^{*}}$ (D)
}

\begin{abstract}
Background: By the authors Janicke (IBJparticle, Eine Implementierung des Ausbreitungsmodells. Bericht IBB Janicke, 2000; AUSTAL2000, Programmbeschreibung, Dunum, 2002), Germany, for the calculation of the dispersion of air pollutants under the designation AUSTAL2000 a "Model-based assessment system for the plant-related pollution control" is developed. This propagation model is declared binding in the Federal Republic of Germany for application. All other model developers have to validate their algorithms on the provided reference solutions. However, for example, Schenk (AUSTAL2000 ist nicht validiert. Immissionsschutz 01.15, pp 10-21, 2015a; Replik auf den Beitrag "Erwiderung der Kritik von Schenk an AUSTAL2000 in Immissionsschutz 01/2015". Immissionsschutz 04.15, pp 189-191, 2015b; Environ Ecol Res 5(1):45-58, 2017), Germany, demonstrates that these reference solutions are flawed. Main sentence and mass conservation theorem are violated. In various publications and other statements by Trukenmüller et al. (Erwiderung der Kritik von Schenk an AUSTAL2000 in Immissionsschutz 01/2015. Immissionsschutz 03/2015, S. 114-126, 2015); Trukenmüller (Äquivalenz der Referenzlösungen von Schenk und Janicke. Abhandlung Umweltbundesamt Dessau-Rosslau, IBS Archiv, S. 1, 2016; Stellungnahmen Umweltbundesamt vom 10.02.2017 und 23.03.2017. DessauRosslau, IBS Archiv, S. 1-15, 2017), Umweltbundesamt Deutschland, the objections raised by Schenk (AUSTAL2000 ist nicht validiert. Immissionsschutz 01.15, pp 10-21, 2015a; Replik auf den Beitrag "Erwiderung der Kritik von Schenk an AUSTAL2000 in Immissionsschutz 01/2015". Immissionsschutz 04.15, pp 189-191, 2015b; Environ Ecol Res 5(1):45-58, 2017), Germany, are denied and it is vehemently disputed.

Results: In this paper, the identified contradictions are analyzed in depth and the results of all studies are summarized. The correct reference solution is specified. The authors of the AUSTAL invoke an allegedly universal agreement $F_{C}=c_{0} \cdot v_{d}$, which was approved by Venkatram and Pleim (Atmos Environ 33:3075-3076, 1999), USA; should be justified. However, it turns out to be embarrassing that they can not be read there. Moreover, it is shown that in Venkatram and Pleim (Atmos Environ 33:3075-3076, 1999), USA; described relationship between deposition and sedimentation is not applicable. A correction is required. There is also evidence that because of a lack of physical basics soil concentrations must be calculated in a tricky way. Because of the undisputed importance of the agreement $F_{c}=c_{0} \cdot v_{d}$, this relationship is referred to here as the Janicke Convention.

Conclusions: In summary, the author of this paper concludes that the propagation model AUSTAL is not validated and is not suitable for the calculation of pollutant propagation processes. Deposition, sedimentation and immission are calculated incorrectly. One understands by deposition loss and not storage. Statements of importance for health and safety, such as safety analyzes and hazard prevention plans are to be checked with physically justified model developments.
\end{abstract}

Keywords: AUSTAL2000, Dispersion calculations, Particle model, Sedimentation, Deposition, Air pollutants

\footnotetext{
*Correspondence: ibswettin@web.de

${ }^{1}$ Rosenberg 17, 06193 Wettin-Löbejün, Germany

Full list of author information is available at the end of the article
} 


\section{Background}

In Axenfeld et al. (1984) describes a model for the calculation of dust precipitation, which was later developed into the LASAT propagation model and is explained extensively in Janicke (2001). This propagation model LASAT becomes Trukenmüller et al. (2015) promises to be a "mother model". It serves the authors of Janicke and Janicke (2002) for the development of a "model-based assessment system for plant-related pollution control" called AUSTAL2000. In this context, reference solutions are published for validation, which are already declared mandatory in VDI (2000) according to LASAT for all further model developments. The guidelines state that all further model developments in the Federal Republic of Germany must be based on this "mother model". However, Schenk (2015a) has shown that these reference solutions are all flawed and unsuitable for comparative calculations. The second law of thermodynamics and the law of mass conservation are violated. In Trukenmüller et al. (2015) is contradicted, and one refers to misunderstandings and lack of physics. At the same time, the derivation of the reference solutions will be published for the first time in the almost 30-year history of AUSTAL. In Schenk (2015b) the objections are rejected and it is proved by means of integral sentences that the violation of the main and conservation laws is universal and not limited to those in Janicke and Janicke (2002). In Trukenmüller $(2016)^{1}$ all criticism is ignored. With different defined deposition rates one wants to bring about equivalence of the reference solutions of the AUSTAL and according to Schenk (2015b), however one ignores the fact that the deposition rate is a material constant, which can not be defined at will. Finally, in Trukenmüller (2017) an even different definition of the deposition rate is given. This is now to be explained by the relation $K \cdot \partial c / \partial z+c \cdot v_{s}=c_{0} \cdot v_{d}$, referring to a convention $\mathrm{F}_{\mathrm{c}}=c_{0} \cdot v_{d}$ allegedly contained in Venkatram and Pleim (1999). It is true, however, that there can not be read about such a convention. However, this alleged convention has already been described in Axenfeld et al. (1984) used and explained there with incomprehensible ideas about the occurrence of deposition. The deposition current is to be formed there at a rate at which "... a column rising up on the earth's surface, which contains the material capable of being deposited, runs empty by deposition". It does not explain, however, where this material should be afterwards. Deposition obviously means loss and not storage. The study of the work of Venkatram and Pleim (1999), on the other hand, affirms the fact that the

\footnotetext{
${ }^{1}$ References Trukenmüller $(2016,2017)$ can be requested at ibswettin@web. de and alfred.trukenmueller@uba.de
}

reference equations of the AUSTAL are trivial solutions because of the boundary condition chosen there $c_{0}=0$ and thus $F_{c}=0$. The conclusiveness of this result is stubbornly denied in Trukenmüller (2017). Because of the recurrent importance of the relationship $F_{c}=v_{d} \cdot c_{0}$ in the development of the AUSTAL, it is henceforth referred to as the Janicke Convention. The relationship between deposition and sedimentation rates is described in Venkatram and Pleim (1999) not convincingly described.

In conclusion, in this work, finally, all opinions expressed by Trukenmüller (2017) are refuted. It is proven that the erroneous reference solutions of the AUSTAL not only violate the relevant integral sentences. Mass conservation is also differentially violated because of Janicke's convention. For two case studies, which are described in Janicke (2001), the inconsistency of the reference solutions of the AUSTAL is demonstrated using the example of calculated deposition and sedimentation flows. It also shows that soil concentrations have to be calculated speculatively because of the appearance of an indeterminate expression. The associated thought model describes strange rather a segregation than the spread of air pollutants. In addition, the correct reference solutions are derived and the concentration distributions thus calculated are compared with the faulty graphics of the AUSTAL. It is further shown that the method described in Venkatram and Pleim (1999), the relationship between deposition and sedimentation velocities is erroneous. This result is of considerable interest, since not only the authors of the AUSTAL use these incorrect connections. Also in Simpson et al. (2012) refers to these inadmissible contexts when developing a high-priority Western European transport model. In this work a correction is made. The use of the Janicke Convention justifies the triviality of all reference solutions. This proof is also kept. Finally, critical terms of the authors of the AUSTAL are analyzed. They show little physical understanding of deposition and sedimentation and explain all the differences with the theory of the spread of air pollutants.

\section{Methods}

Mathematics and mechanics are used alone as valid methods of incorruptible evidence to conduct subsequent investigations. It should not be forgotten that even in the field of air pollutants this sword alone is about credibility. Using differential and integral equations, analytical relationships are described and analyzed. As further methods fluidic and thermodynamic doctrines are used to the main and conservation theorems. In addition there are foundations of the theory of momentum, heat and mass transport as well as numerical mathematics.

The primary material is the publications by Axenfeld et al. (1984), Janicke (2000, 2001, 2002), Janicke and 
Janicke (2002), Simpson et al. (2012), Trukenmüller et al. (2015) and Trukenmüller $(2016,2017)$. It describes the theoretical background of the AUSTAL, the algorithms used, the technical application and various case examples for validation.

Basic knowledge of fluid mechanics, numerical mathematics, modeling of the spread of air pollutants and the basics of coupled momentum, heat and mass transport can be found in the textbooks Albring (1961), Berljand (1982), Janenko (1969), Naue (1967), Schlichting (1964), and Truckenbrodt (1989) can be read as secondary knowledge.

\section{Results}

\section{Calculation of deposition and sedimentation using the faulty Janicke's convention \\ Derivation of the faulty reference solution}

In the more than 30-year history of the AUSTAL in Trukenmüller et al. (2015) described for the first time the analytical correlations for the derivation of the reference solution of the AUSTAL. Also in Janicke (2001), where the theoretical foundations of the "mother model" LASAT are explained, can not be read about.

The authors of the AUSTAL use the differential Eq. (1)

$$
-v_{s} \cdot \frac{\partial c}{\partial z}=\frac{\partial}{\partial z}\left(K \cdot \frac{\partial c}{\partial z}\right)
$$

out. This equation describes a one-dimensional and stationary mass transport. It is an ordinary differential equation of the second order. To solve this equation two physically justified boundary conditions are required. In this respect, $v_{s}(\mathrm{~m} / \mathrm{s})$ is the vertical downward sedimentation velocity, $c\left(\mu \mathrm{g} / \mathrm{m}^{3}\right)$ is the concentration in the control room, $K\left(\mathrm{~m}^{2} / \mathrm{s}\right)$ is the diffusion coefficient, and $z(\mathrm{~m})$ is the vertical coordinate. After a single integration you get the differential equation (2)

$$
K \frac{\partial c}{\partial z}+v_{S} \cdot c=F c
$$

where $F c\left(\mu \mathrm{g} /\left(\mathrm{m}^{2} \mathrm{~s}\right)\right)$ is an integration constant. Instead of integrating the inhomogeneous first-order differential equation thus obtained by applying Lagrange's method, the authors of the Austal select a constant concentration distribution to determine $F_{c}(3)$.

$$
c(z)=\text { const. }=c_{i}
$$

as a special solution. Thus, according to the relation (2) for the integration constants $F c$, they obtain the expression (4).

$$
F_{c}=v_{S} \cdot c_{i},
$$

The authors of the AUSTAL subsequently determine the homogeneous solution (5) for Eq. (2).

$$
c_{h}=b \cdot \exp \left(-z \cdot \frac{v_{s}}{K}\right)
$$

where the constant $b\left(\mu \mathrm{g} / \mathrm{m}^{3}\right)$ is to be determined from the first boundary condition of a constant soil concentration. Because of the linearity of Eq. (2), the superposition principle can be applied, after which the general integral is summed up as the sum of the special and the homogeneous solution (6).

$$
c(z)=c_{i}+c_{h}(z)=\frac{F_{c}}{v_{S}}+b \cdot \exp \left(-z \cdot \frac{v_{S}}{K}\right)
$$

receives. If one uses a constant soil concentration $c(0)=c_{0}$ as boundary condition, one can determine the integration constant $b$. Thus, the authors of the AUSTAL finally get Eq. (7)

$$
c(z)=c_{0} \cdot \exp \left(-z \cdot \frac{v_{S}}{K}\right)+\frac{F_{c}}{v_{S}} \cdot\left[1-\exp \left(-z \cdot \frac{v_{S}}{K}\right)\right],
$$

Equation (7) describes the solution of the differential equation (1). However, taking into account the already fulfilled boundary condition $c(0)=c_{0}$ as well as the chosen special solution (3) one already obtains the trivial expression (8)

$$
c(z)=c(0)=\text { const. }=c_{i}=c_{0},
$$

Considering Eq. (4) and concluding with Eq. (8), this triviality is also confirmed by Eq. (7) with $F_{c}=v_{S} \cdot c_{0}(9)$

$$
c(z)=c_{0} \cdot \exp \left(-z \cdot \frac{\nu_{S}}{K}\right)+c_{0} \cdot\left[1-\exp \left(-z \cdot \frac{\nu_{S}}{K}\right)\right]=c_{0},
$$

With this solution, no concentration distributions can be calculated and propagation models can be validated. Taking Eqs. (2) and (4) into consideration, the trivial solution, as expected, differentially satisfies the mass conservation rate (10)

$$
0+v_{S} \cdot \frac{F_{c}}{v_{S}}=F c
$$

Although Eq. (1) is an ordinary differential equation of the second order, only one constraint is satisfied. The authors of the AUSTAL have to realize that with the trivial solution (7) or (9) no concentration distributions can be calculated. Due to the lack of deposition rate $v_{d}(\mathrm{~m} / \mathrm{s})$ as a free parameter, these equations do not allow the determination of deposition currents. The second 
integration constant $F c$ is not determined and still freely selectable.

Instead of determining these by means of a second physically justified boundary conditions, this is determined by the Janicke convention

$$
F_{c}=c_{0} \cdot v_{d}
$$

replaced. A physical justification for the validity of this convention is not given. The authors of the AUSTAL thus obtain Eq. (12)

$$
c(z)=c_{0} \cdot \exp \left(-z \cdot \frac{v_{S}}{K}\right)+\frac{c_{0} \cdot v_{d}}{v_{S}} \cdot\left[1-\exp \left(-z \cdot \frac{v_{S}}{K}\right)\right],
$$

with which finally all reference solutions are determined. However, the use of the Janicke convention according to Eq. (11) violates the differential mass conservation law. In analogy to Eq. (10) one obtains with the relation

$$
0+v_{S} \cdot \frac{F_{c}}{v_{d}} \neq F c
$$

contrary, also the confirmation.

In connection with the introduction of the Janicke Convention, it is called in Trukenmüller et al. (2015) to an alleged generality and refers to Venkatram and Pleim (1999). It is true, however, that one can not read about such a convention there. Later, Trukenmüller (2016) refers to two different definitions of the deposition rate and thus justifies the erroneous reference solution. The authors of the AUSTAL thus want to bring about an equivalence between their own non-correct reference solution (12) and the correct relationship (30) to be derived later. After that, all contradictions would have been cleared up. In addition, reference is again made to Venkatram and Pleim (1999) and again refers to the universality already questioned. In connection with further efforts to clarify all differences, a third definition of the deposition rate is given in Trukenmüller (2017). After that she would be through the relationship

$$
K \cdot \frac{\partial c}{\partial z}+c \cdot v_{S}=c_{0} \cdot v_{d}
$$

established. The deposition rate alone would only be a proportionality factor that parametrizes the deposition and sedimentation flows. This would be the true definition. Again, it is ignored that the deposition rate alone can only be a material constant. Common to all three given definitions is the fact that Trukenmüller (2016, 2017) noticeably avoid describing a thought model that could physically justify the validity of the Janicke convention. One becomes entangled in contradictions and relies on authority rather than mathematics and mechanics. Obviously, one has forgotten that already in Axenfeld et al. (1984) used the Janicke Convention and described a thought model for it. According to this model of thought, the deposition rate is the speed with which "-picturally speaking-... a pillar standing up on the earth's surface, containing the material capable of being deposited, runs empty by deposition". The inequality (13) conclusively confirms that this thought model is identical to the mathematical model used. It is understood by deposition loss and not storage. So it is understandable that the solution (12) violates the law of mass conservation and the II law of thermodynamics. Later, the Janicke models are adopted in VDI (1988), thus establishing a novel doctrine. However, as will be shown, deposition currents are calculated erroneously according to amount and direction. In Trukenmüller $(2016,2017)$, one persistently insists on the validity of the mathematical model. Mathematically and physically justified objections are ignored.

To derive the reference solutions of the AUSTAL, it should be noted in conclusion that the second boundary condition, which describes the penetration of the deposition-capable material into the soil, is not taken into account. It lacks the understanding that mass can not be lost. There is also a lack of insight that the model of thought used and the associated mathematical formulation for describing deposition and sedimentation are not permissible.

\section{Calculation of sedimentation and deposition currents for the case examples $22 a$ and $22 b$ by means of the faulty reference solutions of the AUSTAL2000}

In "Derivation of the faulty reference solution" section the erroneous reference solution of the AUSTAL was derived and discussed. In this section, for the case examples 22a and 22b described in Janicke (2000, 2002), the graphics obtained with the solution (12) are described. The results can be seen in Fig. 1. The deposition current is identical to the diffuse material flow at the bottom. In the case of the faulty reference solution according to Eq. (12), this results in the expression

$$
\dot{m}_{d}=-K \cdot \frac{\partial c}{\partial z}(0)=v_{S} \cdot c_{0}-\mathrm{F}_{\mathrm{c}} \neq-v_{d} \cdot c_{0},
$$

where $\dot{m}_{d}\left(\mu \mathrm{g} /\left(\mathrm{m}^{2} \mathrm{~s}\right)\right)$ describes the deposition current. The negative sign takes into account that the conductive material flow is basically directed against the concentration gradient. A negative concentration gradient causes a positive material flow and vice versa. It can already be seen here that Eq. (15) explains the deposition current incorrectly, since it is formed from the product of deposition velocity and soil concentration $v_{d} \cdot c_{0}$ 


\section{Case 22a, "Sedimentation without De- position" after Janicke (2002)}

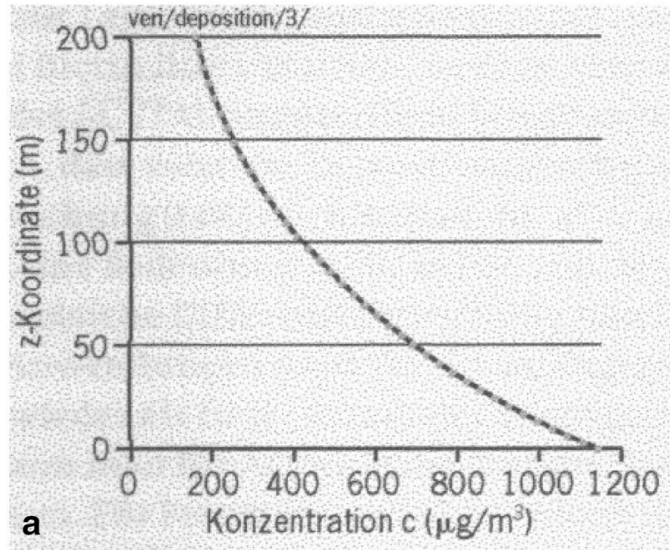

Case 22b, "Sedimentation and Deposition" after Janicke (2002)

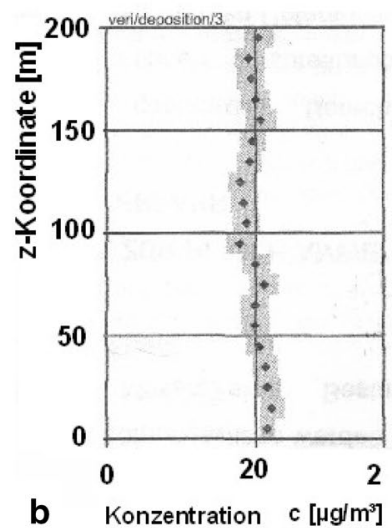

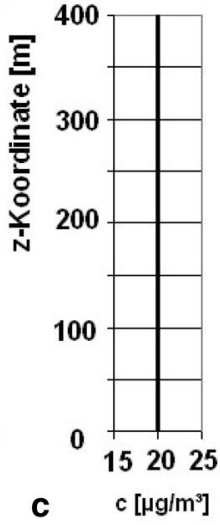

Fig. 1 Concentration distributions for sedimentation with and without deposition; Janicke (2002)

and not otherwise. The control room has a dimension of $L_{x}=1000 \mathrm{~m}, L_{y}=1000 \mathrm{~m}$ and $L_{z}=200 \mathrm{~m}$ in both cases.

First, the case study 22a is of interest, in which, according to Janicke (2002), although sedimentation is allowed, but no deposition should take place. The results are described in Graph a of Fig. 1. With $L_{z}=200 \mathrm{~m}$ the sedimentation velocity is given. The diffusion coefficient is $K=1$. The emissions are released by an evenly distributed volume source over the entire control area. Without further justification, the "specialization $F_{c}=0$ "should continue to apply for this case, which implies according to Eq. (11) also $v_{d}=0$, because one must assume a non-vanishing soil concentration $c_{0}$. If one compares the specification $F_{c}=0$ with Eq. (2), this assumption implies that the propagation process should only be described by a homogeneous differential equation, for which only the homogeneous solution (5) with $b=c_{0}$ applies can be. Taking into account the definition of the deposition rate given in Trukenmüller (2017) according to Eq. (14), this assumption implies a vanishing conductive mass transport as well as a non-existent sedimentation stream. This leads to the conclusion that $F_{c}=0$ can only be equated with a nonexistent emission. The other possibility that both transports cancel each other out also expresses a missing emission. This case is comparable to solving an eigenvalue problem according to Eq. (2) and is more theoretical than practical. In the case of practical applications, immissions can occur only in the presence of emissions, so that the barometric height distribution according to Eq. (5) can not be considered as a solution of the eigenvalue task (2) for propagation calculations. Despite this inadmissibility one wants to make believe with the graphic a, one can compute concentration distributions with missing emissions. However, the authors of the AUSTAL have the difficulty that no calculation equation for the soil concentration is available. Because of the given propagation parameters with $F_{c}=0$ and $v_{d}=0$, the relation $F_{c}=c_{0} \cdot v_{d}$ results in an indefinite expression $c_{0}=0 / 0$, which allows any numerical value. Without specifying a calculation rule, a soil concentration of $c_{0}=1100.6$ is given. One would have to know that a validation of propagation models without knowledge of the algorithm used is not possible. It is up to the reader to find out this calculation rule. It turns out that the soil concentration, contrary to all ideas for calculating the spread of air pollutants, is determined speculatively. But not only this contradiction is objectionable. According to the prerequisite, no deposition should take place for the case 22a. However, this would presuppose a vanishing concentration gradient on the ground for $z=0$, but this can not be seen from Eq. (15). According to Eq. (15), a deposition current of $\dot{m}_{d}=v_{s} \cdot c_{0}-F_{c}=0.01 \cdot 1100.6-0 \approx 11$ is calculated, which, however, precludes the assumption without deposition. The negative concentration gradient calculated incorrectly on the ground according to Eq. (12) forces a material flow in the direction of the positive height coordinate. However, a deposition current is directed towards the ground and not vice versa in the free atmosphere. It is calculated incorrectly in terms of amount and direction, which is why the II. Law of thermodynamics is violated. The calculated concentration distribution also suggests that the source of the source should be located in the ground and not evenly 
distributed as a volume source throughout the control area. Already the consideration of the graphic a excites unrest.

In the case study 22b, one starts from the same control area again, but deposition and sedimentation should equally occur here. The results are described in Graph b of Fig. 1. The rate of deposition and the rate of sedimentation are identical and are $v_{s}=v_{d}=0.05$. The diffusion coefficient is again $K=1$. The emission with a strength of $F_{c}=1$ is to be released at a level of $200 \mathrm{~m}$. In contrast to case example 22a, a calculation equation is available here for determining the soil concentration. For this Eq. (11) $F_{c}=c_{0} \cdot v_{d}$ is used again, and the soil value is given as $c_{0}=F_{c} / \cdot v_{d}=1 / 0.05=20$. According to the prerequisite, a deposition should take place for this case example. However, this would require a concentration gradient on the ground for $z=0$ that is different from zero. However, such a concentration curve can not be seen in the graphic b. The deposition current is again calculated according to Eq. (15) and is $\dot{m}_{d}=v_{s} \cdot c_{0}-F_{c}=0.05 \cdot 20-1=0$. It turns out that no deposition can take place, which contradicts the assumption with deposition. The deposition current has to be different from zero and the depositable material must diffuse into the adjacent soil. Again, the deposit current is calculated incorrectly in terms of magnitude and direction, which also contradicts the II. Law of thermodynamics. As regards the situation of the source in $200 \mathrm{~m}$, opposition is again to be reported. The concentration curve according to Graph b does not reveal a high-altitude source. The conditions also do not change when the control room is expanded to graphic c on. One does not understand how the differential equation (1) or the analytic solution (12) could even consider sources at different heights. The mathematical model that applies to this only describes the differential equation (16)

$$
\frac{\partial c}{\partial t}+v_{i} \cdot \frac{\partial c}{\partial x_{i}}=\frac{\partial c}{\partial x_{i}}\left(K \cdot \frac{\partial c}{\partial x_{i}}\right)+\dot{q}
$$

where $t(\mathrm{~s})$ denotes the time coordinate, $x_{i}(\mathrm{~m})$ observing the summation convention, the different spatial directions, $v_{i}(\mathrm{~m} / \mathrm{s})$ the flow velocities, and $\dot{q}\left(\mu \mathrm{g} /\left(\mathrm{m}^{3} \mathrm{~s}\right)\right)$ a possible source term. The authors of the AUSTAL do not use this relationship but Eq. (1).

In the long history of AUSTAL by Axenfeld et al. (1984) on the "mother model" LASAT according to Janicke (2001) and VDI (1988) until the development of a modelbased assessment system for occupational immission protection according to Janicke and Janicke (2002) is in Trukenmüller et al. (2015) published for the first time the derivation of the reference solutions of this dispersion model. In this section, the case examples $22 \mathrm{a}$ and $22 \mathrm{~b}$ were used as an example to show which distortions the use of the Janicke Convention leads to.

\section{The soil concentration for case 22a must be calculated speculatively}

For the case study 22a it is stated in "Calculation of sedimentation and deposition currents for the case examples $22 \mathrm{a}$ and $22 \mathrm{~b}$ by means of the faulty reference solutions of the AUSTAL2000" section that the calculation of the soil concentration $c_{0}=0 / 0$ results in an indeterminate expression. The soil concentration can take any numerical value. It will be interesting to know how the authors of the AUSTAL proceed here.

First of all, it is noticeable that in contrast to the case $22 \mathrm{~b}$, in which the source is supposed to have been located in $200 \mathrm{~m}$, the only exception is a "volume source over the entire computing area". A justification for this is not given. It is stated in this context that the control volume has a total mass pollutant of $100 \mathrm{~kg}$. First one calculates with this information according to Eq. (17)

$$
\bar{c}=\frac{E}{L_{x} \cdot L_{y} \cdot L_{z}}=\frac{100}{200 \cdot 1000 \cdot 1000} \cdot 10^{9}=500,
$$

a mean concentration of $\bar{c}\left(\mu \mathrm{g} / \mathrm{m}^{3}\right)=500$, which has settled after filling the control volume. In this equation, $E(\mathrm{~kg})=100$ also means the total emission. How the pollutant entry takes place, is not explained and is also of little concern. After adjusting the mean concentration in the entire control volume and, as here, no further emissions have to be taken into account, the stationary state with a complete concentration equalization has already been reached. Because of $\partial / \partial t=0, \dot{q}=0$ and $\partial / \partial x_{i}=0$ the differential equations (1) and (16) are fulfilled identically. A further development of the already existing constant concentration profile is not possible because the solution has already been reached. It is therefore unnecessary any further propagation calculation. With $F_{c}=0$, which is true for case 22a, the obtained constant concentration distribution precludes the faulty solution according to Eq. (7). According to Eq. (7), the concentration distribution should follow a barometric altitude distribution. It now has to be explained how a barometric concentration profile can be calculated in a static system and from an equally distributed pollutant admixture. The thought model developed for this purpose assumes that the pollutant particles inside the control room are redistributed by the authors of the AUSTAL so that they follow an exponential function. For this purpose the exponential distribution function according to Eq. (5) $c(z)=c_{0} \cdot \exp \left(-z \cdot v_{s} / k\right)$ is used and the soil concentration $c_{0}$ is considered to be a free parameter, which has to be determined considering the already calculated 
mean concentration of $\bar{c}=500$. It bypasses the indefinite expression. The calculation equation used for this is described by the expression (18).

$$
c_{0}=\frac{\bar{c} \cdot L_{z}}{\int_{0}^{L_{z}} \exp \left(-z \cdot \frac{v_{S}}{K}\right) \cdot d z}
$$

After Trukenmüller et al. (2015), however, we do not use the soil concentration $c_{0}$ determined in this way for $z=0$ but a concentration $c(5 \mathrm{~m})$ at a reference level of $z=5$. This finally gives Eqs. (19) and (20)

$$
c(5 \mathrm{~m})=\bar{c} \cdot \frac{v_{S} \cdot L_{z}}{K} \cdot \frac{1}{\left[1-\exp \left(-\frac{v_{s} \cdot L_{z}}{K}\right)\right]} \cdot \exp \left(-\frac{v_{S}}{K} \cdot 5\right)
$$

$$
K \frac{\partial c}{\partial z}+v_{s} \cdot c=A
$$

where the identity $A \equiv F_{c}$ has to be considered. With a further integration one obtains Eq. (22)

$$
c(z)=\frac{1}{v_{s}} \cdot\left[A+D \cdot \exp \left(-\frac{\mathrm{v}_{\mathrm{s}} \cdot z}{K}\right)\right]
$$

with the integration constants $A\left(\mu \mathrm{g} /\left(\mathrm{m}^{2} \mathrm{~s}\right)\right)$ and $D\left(\mu \mathrm{g} /\left(\mathrm{m}^{2} \mathrm{~s}\right)\right)$. For their determination, the boundary conditions (23) and (24) are used.

$$
c(0)=c_{0}
$$

Equation (20) is to be understood as a numerical value equation with which the soil concentration of $1100.6 \mu \mathrm{g} / \mathrm{m}^{3}$ specified in case 22a was determined. A comparison with Graph a of Fig. 1 confirms the agreement.

The question arises as to how the so-calculated redistribution of pollutant particles can be imagined. A concentration equalization always takes place in the direction of a potential gradient, and not the other way around, according to the second law of thermodynamics without external force. The thought model of the authors of the AUSTAL describes rather a procedural demixing than a method for the calculation of the dispersion of air pollutants with deposition and sedimentation. A procedural demixing requires an energy input, of which there can be no question here. The authors of AUTAL develop a very sophisticated algorithm to disguise the uselessness of their reference solutions in front of the public. This also includes the pollutant input distributed over a "volume source over the entire computing area", which is selected only for the case 22a alone. With this trick one wants to solve the problem that for this case for the calculation of the soil concentration only an indeterminate expression $c_{0}=0 / 0$ is available.

\section{Calculation of deposition and sedimentation on the basis of physically justified boundary conditions (Schenk) Derivation of the correct reference solutions}

To derive the error-free relationship between deposition and sedimentation is again assumed by Eq. (1). After a single integration, Eq. (21)

$$
K \cdot \frac{\partial c}{\partial z}(0)-v_{d} \cdot c_{0}=0
$$

The boundary condition (23) takes into account a constant soil concentration. Equation (24) is derived from the equality of the conductive material flows $K \cdot \partial c / \partial z(0)=K_{B} \cdot \partial c / \partial z_{*}(T)$ at the lower boundary of the control space between the atmosphere and the ground with the relationship (25)

$$
\begin{aligned}
K \cdot \frac{\partial c}{\partial z}(0) & =K_{B} \cdot \frac{\partial c}{\partial z_{*}}(T) \\
& =\frac{K_{B}}{T} \cdot\left(c_{0}-c_{T}\right) \approx \frac{K_{B}}{T} \cdot c_{0} \\
& =v_{d} \cdot \mathrm{c}_{0}
\end{aligned}
$$

at a great depth $T(\mathrm{~m})$ of the soil, the mass concentration $c_{T}\left(\mu \mathrm{g} / \mathrm{m}^{3}\right)$ can be neglected in comparison to the soil concentration, $c_{0} \gg c_{T}$. In Eq. (25), $K_{B}\left(\mathrm{~m}^{2} / \mathrm{s}\right)$ is the effective mass transfer coefficient for the soil, and $z_{*}(\mathrm{~m})$ is the vertical soil coordinate in the interval $T \geq z_{*} \geq 0$. In comparison, the vertical height coordinate $z$ is in the interval $H \geq z \geq 0$, where $H(\mathrm{~m})$ denotes the maximum height of the control room. Immediately at the boundary between the atmosphere and the ground, $z=0$ and $z_{*}=T$ apply, as can be seen from Eq. (25). Equation (25) yields the boundary condition (24) and also the definition of the deposition velocity $v_{d}=K_{B} / T$. In Eq. (25) the derivative $\partial c / \partial z_{*}=\left(c_{0}-c_{T}\right) / T$ of expression (27) is used. 


\section{Case 22a, "Sedimentation without De- position" after Schenk (2015-2)}

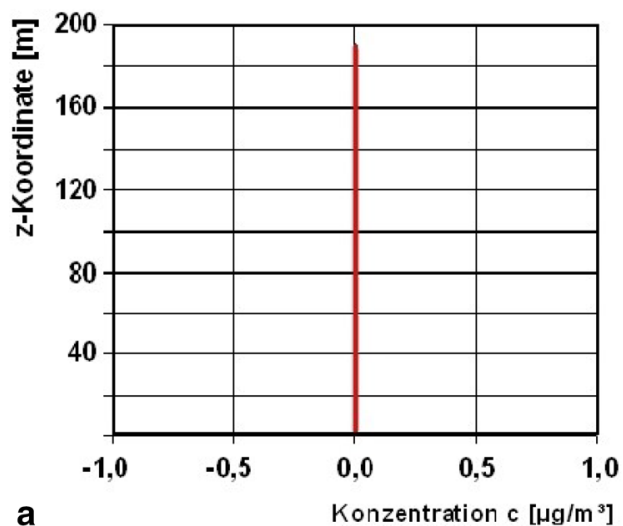

Case 22b, "Sedimentation and Deposition" after Schenk (2015-2)

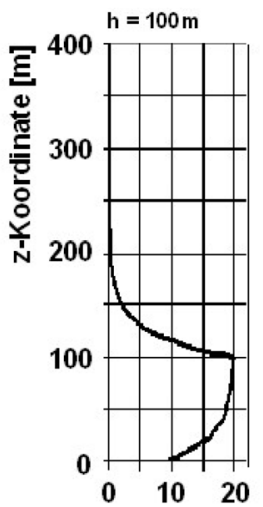

b

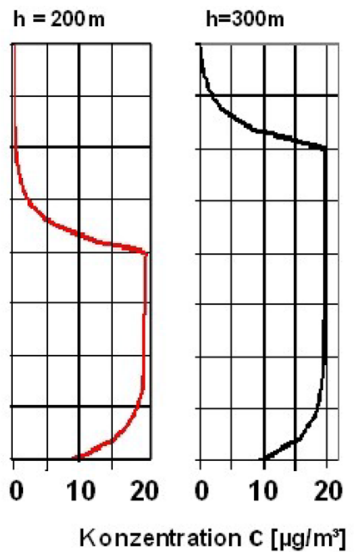

Fig. 2 Concentration distributions for sedimentation with and without deposition, Schenk (2015b)

Due to vanishing sedimentation velocity $v_{s}=0$ and constant diffusion coefficient, the differential equation (25) with a linear concentration distribution according to the relation (27) applies for conductive transport in soil considering Eq. (1).

$$
\begin{aligned}
& \frac{\partial^{2} c}{\partial z_{*}^{2}}=0 \\
& c\left(z_{*}\right)=\frac{c_{0}-c_{T}}{T} \cdot z_{*}+c_{T}
\end{aligned}
$$

With the described boundary conditions (23) and (24), the integration constants $A$ and $D$ can be determined and Eqs. (28) and (29) result.

$$
\begin{aligned}
& A=c_{0}\left(v_{s}+v_{d}\right) \\
& D=-c_{0} \cdot v_{d}
\end{aligned}
$$

Equation (22) gives the relation (30)

$$
c(z)=c_{0} \cdot \frac{v_{s}+v_{d}}{v_{s}} \cdot\left[1-\frac{v_{d}}{v_{s}+v_{d}} \cdot \exp \left(-\frac{v_{s}}{K} \cdot z\right)\right],
$$

The total mass flow $\dot{m}_{g}\left(\mu \mathrm{g} /\left(\mathrm{m}^{2} \mathrm{~s}\right)\right)$ is described by Eq. (31). For the deposition and sedimentation flows, $\dot{m}_{d}\left(\mu \mathrm{g} /\left(\mathrm{m}^{2} \mathrm{~s}\right)\right)$ and $\dot{m}_{s}\left(\mu \mathrm{g} /\left(\mathrm{m}^{2} \mathrm{~s}\right)\right)$, the expressions (32) and (33) are given.

$$
\begin{aligned}
& \dot{m}_{g}=c_{0} \cdot\left(v_{s}+v_{d}\right) \\
& \dot{m}_{d}=c_{0} \cdot v_{d}
\end{aligned}
$$

$$
\dot{m}_{s}=c_{0} \cdot v_{s}
$$

The boundary condition (24) can, for example, also be read in Berljand (1982). It is older than the field of knowledge of the modeling of the spread of air pollutants, so that an author for this can no longer be specified. It simply results from the understanding of the equality of conductive flows and that mass can not be lost. Equation (30) describes the concentration distribution as a solution of the differential equation (1) and the function of deposition and sedimentation rates $\mathrm{v}_{\mathrm{d}}$ and $\mathrm{v}_{\mathrm{s}}$ as free parameters. The diffusion coefficient is also kept variable. With this relationship (30), deposition and sedimentation can be described free of defects.

\section{Calculation of sedimentation and deposition for case studies $22 a$ and $22 b$ using the correct reference solution}

"Derivation of the correct reference solutions" section described the correct solution of the differential equation (1). In this section, the concentration distributions obtained therewith are calculated for the already known case examples $22 \mathrm{a}$ and $22 \mathrm{~b}$ and compared with the faulty representations of "Calculation of sedimentation and deposition currents for the case examples 22a and 22b by means of the faulty reference solutions of the AUSTAL2000" section. The results are explained in Graphs a and $b$ of Fig. 2 of this section. They are to be compared with the graphics a and b of "Calculation of sedimentation and deposition currents for the case examples 22a and $22 \mathrm{~b}$ by means of the faulty reference solutions of the AUSTAL2000" section. The geometrical dimensions of the control room and the flow parameters of the case examples $22 \mathrm{a}$ and $22 \mathrm{~b}$ are already known. In contrast to 
Eq. (15) one obtains the expression for the deposition current

$$
\dot{m}_{d}=-K \cdot \frac{\partial c}{\partial z}(0)=-v_{d} \cdot c_{0},
$$

It can be seen that the deposition current is formed solely from the product of deposition rate $v_{d}$ and soil concentration $c_{0}$ and not differently according to Eq. (15).

First of all, the case example 22a with sedimentation without deposition is again of interest. For this, the graphic a of Fig. 2 is to be considered. Because of $A=F_{c}=0, \quad \mathrm{a}$ vanishing soil concentration $c_{0}=A /\left(v_{s}+v_{d}\right)=0 /(0.01+0)=0$ results in the entire control room according to Eq. (28), which is in contradiction to Graph a of "Calculation of sedimentation and deposition currents for the case examples 22a and 22b by means of the faulty reference solutions of the AUSTAL2000" section. The result follows the simple logic that no emissions can occur in the absence of emissions in the entire control volume. According to the assumption, no deposition should take place, which is why no deposition current can be observed even according to Eq. (34). The derivation of Eq. (30) for the soil is calculated as a vanishing concentration gradient $\partial c / \partial z(0) \equiv 0$ and thus $\dot{m}_{d}=-K \cdot \partial c / \partial z(0)=1 \cdot 0=0$, which is confirmed by the concentration curve in Graph a of Fig. 2.

For the case $22 \mathrm{~b}$ the results are described by the Graph b of Fig. 2. According to the authors of the AUSTAL, the source is said to have been at a height of $h(\mathrm{~m})=200$. However, it should be noted that the differential equation (1) is not suitable at all for considering sources at different heights. Also in the reference solution of the authors of the AUSTAL (12) no free parameter is recognizable, which allows to vary source heights. In fact, only the differential equation (16), which was simplified according to Eq. (35) for the present case, can be responsible for such tasks

$$
\frac{\partial c}{\partial t}-v_{S} \cdot \frac{\partial c}{\partial z}=K \cdot \frac{\partial^{2} c}{\partial z^{2}}+\dot{q}
$$

Due to a lack of analytical solution, this equation was solved numerically for the present task. The control room has been extended to show the complete solution history. Schenk (1980) describes the numerical algorithm used for this purpose. It is a general method for solving the three-dimensional non-stationary differential equations of momentum, heat and mass transport based on the interim step method according to Janenko (1969). In this respect, this simple task concerns a welcome application here. However, as the authors of the AUSTAL have determined the graphic $\mathrm{b}$ of Fig. 1, is uncertain. For further discussion, the graphic b of Fig. 2 highlights the case $h=200$. The soil concentration is $c_{0}=10$ and in $200 \mathrm{~m}$ the concentration is $c(200) \approx 20$. Because there is the source there, as expected, there is the maximum concentration. In the further course of concentration with the height, a considerably greater decrease of the concentrations can be observed in comparison to the area below the source. This can be explained by the fact that there the conductive part of mass transport changes its sign. Because of a positive concentration gradient for $z=0$, the deposition current of $\dot{m}_{d}=-v_{d} \cdot c_{0}=-0.05 \cdot 10$ $=-0.5$ is directed against the positive $\mathrm{z}$-axis in the direction of the ground. In the interval up to $z=200$ the numerical results agree very well with those of the analytic solution according to Eq. (30). This results in $c(0)=10 \cdot(0.05+0.05) / 0.05 \cdot[1-0.05 /(0.05+0.05)$. $1]=10$ and $c(200)=10 \cdot(0.05+0.05) / 0.05 \cdot[1-0.05 /$ $(0.05+0.05) \cdot \exp (-200 \cdot 0.05 / 1] \approx 20$, which again speaks for the quality of the numerical method. To prove its generality, the concentration distribution was still determined for the heights and. The location of the springs is very easy to recognize.

Concluding to this section, it can be estimated that the correct integral (30) of the differential equation (1), in contrast to Eq. (12), correctly describes the occurrence of deposition and sedimentation. The calculated concentration courses are plausible and physically justified.

\section{Relationship between deposition and sedimentation Incorrect calculation of deposition and sedimentation according to Venkatram and Pleim (1999)}

The authors of the AUSTAL refer in all their publications to the reference Venkatram and Pleim (1999). The results there are intended to prove the validity of the Janicke Convention. An examination of this work, however, concluded that the authors of Venkatram and Pleim (1999) were more likely to derive an analytical link between deposition and sedimentation than to confirm any conventions. If one were able to calculate sedimentation velocities directly by sedimentation rates, then this would be of great use in the field of modeling the spread of air pollutants. However, the study brought the result that no convention can be read. The correctness of the relation between deposition and sedimentation can not be confirmed either. The following considerations are of interest here.

In deriving the relationship between deposition and sedimentation, the authors of Venkatram and Pleim (1999) of the differential equation already known from Eq. (2) 


$$
K \frac{\partial c}{\partial z}+v_{S} \cdot c=F
$$

again taking into account the indentities $F \equiv F_{c} \equiv A$. Equation (36) is an ordinary first-order inhomogeneous differential equation. In the solution process, the relationship (37) is obtained analogously to Eq. (22)

$$
c(z)=\frac{1}{v_{S}} \cdot\left\{F+D \cdot \exp \left[-\mathrm{r}(\mathrm{z}) \cdot \mathrm{v}_{\mathrm{S}}\right]\right\},
$$

where $D$ is to be understood as an integration constant which is to be determined by means of a boundary condition. $F$ is given by the relation (36). For the determination of $D$ the boundary condition (38) is used. It says that the soil concentration is identical to zero.

$$
c(0)=0,
$$

Thus, the integration constant $D$ is calculated to Eq. (39)

$$
D=-F,
$$

as a solution of Eq. (36) the relation (40) is given

$$
c(z)=\frac{F}{v_{S}} \cdot\left\{1-\exp \left[-r(\mathrm{z}) \cdot v_{S}\right]\right\},
$$

In this equation, $r(z)$ according to Eq. (41) means the reciprocal conductive transport velocity.

$$
r(z)=\int_{0}^{z} \frac{d z}{K(z)}=\frac{z}{K} \text { für } K=\text { const. }
$$

The smaller the transport speed, the greater the resistance.

For the relationship between deposition and sedimentation, the authors of Venkatram and Pleim (1999) below describe the relationship (42)

$$
v_{d}=\frac{v_{S}}{1-\exp \left[-\mathrm{r}(\mathrm{z}) \cdot \mathrm{v}_{S}\right]},
$$

which however can not be reconstructed. A comparison of coefficients between Eqs. (40) and (42) reveals that the expression (43)

$$
F=c(z) \cdot v_{d}
$$

has been used. However, the authors of Venkatram and Pleim (1999) overlook that Eq. (36) according to (2) is already the first integral of the differential equation (1). The constant $F$ is also to be regarded as an integration constant and can not be somehow determined according to Eq. (43). Likewise, the constant $F$ can not be a variable $F(z)$ at the same time. Also, the use of the deposition rate $v_{d}$ in Eq. (43) is not physically substantiated.

The constant $F$ can not be determined arbitrarily. The constant $F$ can not be a function of $z$. The deposition rate $v_{d}$ is used inappropriately. Because of these three reasons, the correctness of Eq. (42) is not guaranteed. Their use is not allowed.

Nevertheless, the authors of the AUSTAL interpret Eq. (43) as their Janicke convention $F_{c}=c_{0} \cdot v_{d}$, which is not recognizable and is not justified physically. Because of the boundary condition (38), the convention would result anyway $F_{c}=0$, which calls into question the entire theory of reference solutions of the AUSTAL. But not only the founders of AUSTAL use these misleading descriptions of deposition and sedimentation to model the spread of air pollutants. Also the authors of Simpson et al. (2012) can be misleading in connection with the development of "The EMEP MSC-W chemical transport model".

\section{Relevant calculation of deposition and sedimentation (Schenk)}

The author of this article criticizes the results of Venkatram and Pleim (1999) regarding the description of deposition and sedimentation. A correction is required.

If one starts from Eq. (30), the relation (44) is obtained by a simple conversion.

$$
v_{d}=v_{S} \cdot \frac{\frac{\mathrm{c}(\mathrm{z})}{\mathrm{c}_{0}}-1}{1-\exp \left[-r(z) \cdot v_{S}\right]}
$$

If one uses the exact solution for the concentration distribution $c(z)$, the identities $v_{d} \equiv v_{d}$ and $v_{s} \equiv v_{s}$ result. In the case of different applications, however, it is possible to determine an average deposition rate $\bar{v}_{d}$ from a measured arbitrary concentration distribution. For this purpose, the integral (45) is formed

$$
\bar{v}_{d}=\frac{v_{S}}{H} \cdot \int_{0}^{\mathrm{H}} \frac{\frac{\mathrm{c}(\mathrm{z})}{\mathrm{c}_{0}}-1}{1-\exp \left(-r(z) \cdot v_{S}\right)} \cdot d z,
$$

which can be determined approximately numerically. $H(\mathrm{~m})$ means the height of the viewing area.

With the intention to use an analytic relationship, the estimate $c(z) \leq c_{\max }$ can be used for all $z$ one persistently insists on

$$
\begin{aligned}
& \text { and } \Delta c=c_{\max }-c_{0} \text { the integral (46) } \\
& \qquad \bar{v}_{d}^{*}=\frac{\Delta c \cdot v_{s}}{c_{0} \cdot H} \cdot \int_{\mathrm{z}_{0}}^{\mathrm{H}} \frac{d z}{1-\exp \left(-\frac{v_{s} \cdot z}{K}\right)}
\end{aligned}
$$




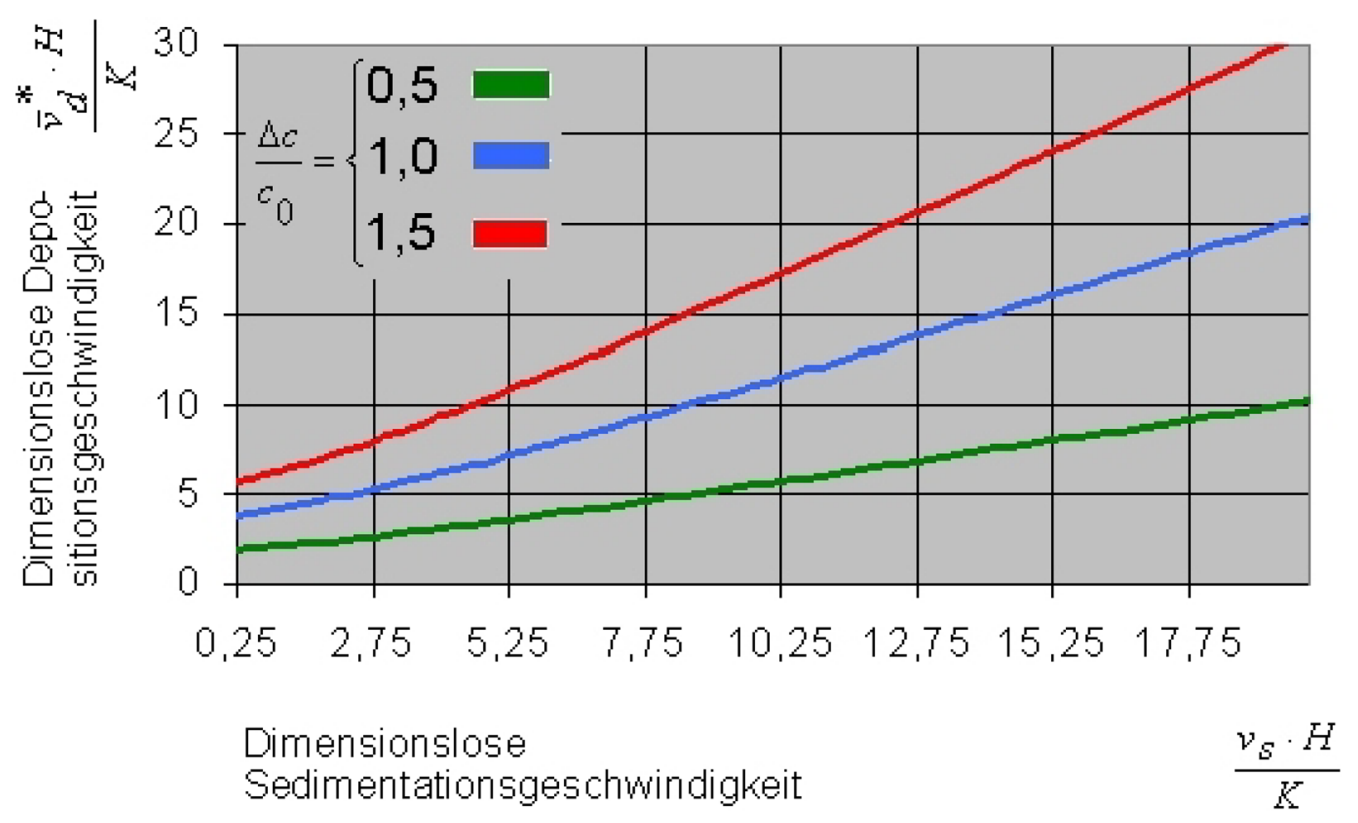

Fig. 3 Approximate calculation of deposition rates

receive. For this integral results after Gradstein and Ruschik (1963) a solution. This describes the relationship (47)

$$
\bar{v}_{d}^{*}=\frac{\Delta c}{c_{0}} \cdot \frac{K}{H} \cdot\left\{\frac{v_{s}}{K} \cdot\left(H-z_{0}\right)+\ln \left[\frac{1-\exp \left(-\frac{v_{s} \cdot H}{K}\right)}{1-\exp \left(-\frac{v_{s} \cdot z_{0}}{K}\right)}\right]\right\},
$$

where $z_{0}(\mathrm{~m})$ is positively small enough in the vicinity of the singularity $z=0 . \bar{v}_{d}^{*}(\mathrm{~m})$ approximates the average deposition rate $\bar{v}_{d}^{*} \approx \bar{v}_{d}$.

In connection with practical applications, one uses a dimensionless notation according to Eq. (48)
The inadmissibility of the Janicke Convention justifies the triviality of all reference solutions of the AUSTAL2000 As already stated, the authors of the AUSTAL and Trukenmüller et al. (2015), Trukenmüller $(2016,2017)$ justifying the Janicke Convention $F_{c}=c_{0} \cdot v_{d}$ on Venkatram and Pleim (1999). Because of the boundary condition (38) $c_{0}=0$, the banality (49)

$$
F=F_{c}=0,
$$

The inadmissibility of Janicke convention is proved by Eq. (49). Their use for the development of models for the calculation of the spread of air pollutants is inadmissible. Deposition and sedimentation as well as immissions are

$$
\frac{\bar{v}_{d}^{*} \cdot H}{K}=\frac{\Delta c}{c_{0}} \cdot\left\{\frac{v_{s} \cdot H}{K} \cdot\left(1-\frac{z_{0}}{H}\right)+\ln \left[\frac{1-\exp \left(-\frac{v_{s} \cdot H}{K}\right)}{1-\exp \left(-\frac{v_{s} \cdot H}{K} \cdot \frac{z_{0}}{H}\right)}\right]\right\}
$$

prefer. For example, for the intervals $0.25 \leq v_{s} \cdot H / K \leq 20$, $1.91 \leq \bar{v}_{d}^{*} \cdot H / K \leq 30.65$ and $z_{0} / H=0.025$ and $\Delta c / c_{0}=0.5,1.0,1.5$, the following graph of Fig. 3 is obtained.

For the case study 22b described here, $H=200$, $K=1, \quad v_{s}=0.05, \quad v_{s}=0,05, \quad \Delta c / c_{0}=\left(c_{\max }-c_{0}\right) / c_{0}=$ $(20-10) / 10=1$ and $v_{s} \cdot H / K=10$ give the dimensionless deposition rate $\bar{v}_{d}^{*} \cdot H / K=11.256$. From this, the approximate average deposition rate is determined $\bar{v}_{d}^{*}=0.056$. The exact value is $v_{d}=0.05$. Improvements are achieved when the integral (45) is solved numerically. calculated incorrectly.

\section{Peculiar concepts}

The object of the investigations was solely analytical and numerical considerations to solve a common differential equation for the description of a one-dimensional pollutant transport process. In the context of the model development of the AUSTAL and the associated reference solutions, strange terminology is used, which spreads confusion rather than education. So one speaks 
for example from a homogenizing and means diffusion. Homogenization, however, just like demixing and shredding, is one of the basic operations of process engineering. In your case, the mass transfer occurs through energy input, while in the case of diffusion for concentration equalization a potential gradient is responsible. When homogenizing, one notices strange oscillations at the region boundaries, which are not further explained. Whether numerical instabilities are responsible for this remains uncertain, because the authors of the AUSTAL themselves write that some solutions do not converge. Proofs for the numerical stability of their algorithms are not kept. It is calculated with so-called homogeneous and inhomogeneous turbulence approaches and actually means the effective diffusion, which, as is known, can also be spatially different. The belief is spread that one masters the modeling of turbulent flows, even though the equations of fluid mechanics are not the subject of all considerations. A description of the AUSTAL explains that calculations with so-called homogeneous turbulence and spatially variable step size can not be performed. In another report, however, such simulations are discussed. The reader is confused. Within closed buildings AUSTAL calculates concentrations. It is explained that Staupartikel vertical house walls can not "see" and therefore want to go through. In fact, it should be used to hide a careless way of programming. With mass / time, mass / (time" length ${ }^{2}$ ) and "volume source over the entire computing area", three different source term definitions are given. However, a "volume source over the entire computing area" is unknown in the field of modeling the spread of air pollutants. It is chosen only to mask inefficiencies in the solution process. In fact, only point sources or mass flow rates are of interest. Deposition speeds are defined as desired. 3D wind fields are to be used for validation. In fact, one uses the rigid rotation of a solid in the plane.

The theoretical foundations of AUSTAL are also challenged by these strange views.

\section{Discussion and summary of the results}

As part of a non-university research in the field of propagation of air pollutants a model for the "Investmentrelated emission protection" called AUSTAL2000 is developed in the Federal Republic of Germany, Axenfeld et al. (1984). This model development begins with the model LASAT after Janicke (2001). This propagation model, including its theoretical foundations, is declared binding for all further model developments with reference to VDI (1988). AUSTAL provides reference solutions that other model developers use to validate their algorithms. Schenk (2015a) demonstrates that all reference solutions are flawed. Even the authors of the AUSTAL could not have validated their propagation model. In Trukenmüller et al. (2015), the authors feel obliged to respond to the allegations. In this context, the derivation of the reference solutions is published for the first time in the more than 34-year history of AUSTAL. The errors and contradictions identified therein are explained in Schenk (2015b). The correct solution is given. It is also described that the convention used $\mathrm{F}_{\mathrm{c}}=c_{0} \cdot v_{d}$ is inadmissible and useless. By unbelievable definitions of the deposition speed one wants to prove its validity in Trukenmüller (2016). However, this attempt fails because the deposition rate is a material constant and can not be defined as desired. One refers to Venkatram and Pleim (1999) and wants to make believe, there this connection would be described physically justified. Due to obvious contradictions, a further definition of the deposition rate is given below in Trukenmüller (2017) with $K \cdot \partial c / \partial z+c \cdot v_{s}=c_{0} \cdot v_{d}$. Afterwards, this parameterizes the convective and conductive material flows. Thus one wants to prove the general validity of the convention $\mathrm{F}_{\mathrm{c}}=c_{0} \cdot v_{d}$ and refers again to Venkatram and Pleim (1999) and other authors, e.g. Simpson et al. (2012). Again, this convention would be used, as it is claimed. It turns out, however, that these references are not justified. Neither in Venkatram and Pleim (1999) still in Simpson et al. (2012), this convention is the subject of consideration. In Venkatram and Pleim (1999) is more concerned with the derivation of an analytical relationship between deposition and sedimentation rates than with the justification of any convention. In Simpson et al. (2012) only the relationship between deposition and sedimentation according to Venkatram and Pleim (1999), but not the Convention $\mathrm{F}_{\mathrm{c}}=c_{0} \cdot v_{d}$. Only the authors of the AUSTAL use this convention, which is why it has to be called the Janicke Convention. It can not be said that they are universally valid. Nevertheless, according to VDI (1988), this convention is adopted as a valid legal opinion in the "Scientific Handbook for Practices in Environmental Planning" of the Federal Environment Agency. With the doubtful research results Axenfeld et al. (1984) to develop a new theory of the spread of air pollutants. The authors of the AUSTAL and Trukenmüller (2016) as well as Trukenmüller (2017) ignore all substantiated objections. They insist on the validity of the Janicke Convention and authoritatively demand their recognition. The use of the Janicke Convention in all publications on air pollution control of the Federal Environmental Agency and in VDI (1988) has led to considerable distortions in the modeling of the spread of air pollutants. It is therefore justified to take a deeper look at the validity of the Janicke Convention, which is the subject of this work. Also the work of Venkatram and Pleim (1999) is critically examined.

The results of this article can be summarized. 
It is shown that it is in the Trukenmüller et al. (2015) is a trivial relationship. Mathematics and mechanics as well as the fundamentals of the theory of ordinary differential equations have to be considered.

There is no free parameter in the solution to calculate deposition currents. Only the first boundary condition of a constant soil concentration is considered. This difficulty is overcome by the arbitrary introduction of the Janicke Convention. It is explained that this differentially no mass conservation is guaranteed. One understands by deposition loss and not storage. The thought model for this purpose is defined according to Axenfeld et al. (1984), the deposition rate as the speed after the "-picturally speaking -... a rising on the surface of the earth, the column containing the depositionable material, by idling idle". The concentration distributions calculated with the faulty reference solution for the case examples 22a and 22b, which are described in Janicke and Janicke (2002) show that deposition and sedimentation are described inaccurately. The law of mass conservation and the II law of thermodynamics are violated. For the calculation of the soil concentration in case $22 \mathrm{a}$, one obtains an indeterminate expression, which is why deviating from all other test cases, one must introduce a "volume source over the entire computing area" distributed there. The pollutant particles must be redistributed by the authors of the AUSTAL in the control volume so that they follow a barometric height distribution. However, this redistribution is more a result of procedural segregation rather than a calculation of the spread of air pollutants with physically based balance equations.

In contrast to the erroneous considerations of the authors of the AUSTAL the correct solutions are described. They assume that due to the equality of the conductive material flows at the lower limit of the control room on the ground mass can not be lost. The correct solutions thus obtained are used for the considered case studies for the erroneous concentration distributions according to Janicke and Janicke (2002). The law of mass conservation and the II law of thermodynamics are fulfilled.

In support of the Janicke Convention, the authors of the AUSTAL refer to Venkatram and Pleim (1999). For the purpose of enlightenment, the author of this work engrossed with the results. The authors of Venkatram and Pleim (1999) develop an analytical relationship between the deposition and sedimentation rates. An argument with any conventions does not take place. However, it should be noted that the authors of Venkatram and Pleim (1999) disregard the fact that their initial equation is already the first integral of the relevant balance equation for the propagation and the disturbance function describes a constant quantity. The constant $F$ can not be set as variable $F(z)=c(z) \cdot v_{d}$ at the same time. Again, the approach is chosen arbitrarily and physically not justified. The authors of the AUSTAL follow this erroneous view and see obviously inadmissible in a confirmation of the Janicke Convention $\mathrm{F}_{\mathrm{c}}=c_{0} \cdot v_{d}$. They ignore the ones in Venkatram and Pleim (1999) used boundary condition $c_{0}=0$. The result is the expression $\mathrm{F}_{\mathrm{c}}=0$. The Janicke Convention is not confirmed.

The author of this work doubts the validity of the in Venkatram and Pleim (1999) derived relationship between deposition and sedimentation. A correction is required. The result is an integral equation for which, according to Gradstein and Ruschik (1963) can be given an approximate solution. For the case example 22b, a numerical evaluation is made. The deposition rate can be calculated with $12 \%$ a deviation of about.

Finally, it is shown that for all reference cases $F_{c}=0$ applies. The use of the Janicke Convention is inadmissible. This results in an eigenvalue task for all test examples. Their solution is out of the question for practical applications. It has no relation to the modeling of the spread of air pollutants.

\section{Conclusions}

Mathematics and mechanics proved that the propagation model AUSTAL2000 can not be validated. This applies to all further model developments that have been validated on the faulty reference solutions. Security plans and, for example, security analyzes prepared with AUSTAL are to be reviewed. These statements are also true for the "parent model" LASAT.

\section{Abbreviations}

A: constant of integration, $\mu \mathrm{g} /\left(\mathrm{m}^{2} \mathrm{~s}\right)$; b: constant of integration, $\mu \mathrm{g} / \mathrm{m}^{3}$; c: concentration, $\mu \mathrm{g} / \mathrm{m}^{3} ; C_{0}$ : concentration, $\mu \mathrm{g} / \mathrm{m}^{3} ; \bar{c}$ : steady state concentration, $\mu \mathrm{g} /$ $\mathrm{m}^{3} ; c_{T}$ : concentration in soil depth, $\mu \mathrm{g} / \mathrm{m}^{3} ; c_{h}$ : homogeneous solution, $\mu \mathrm{g} / \mathrm{m}^{3}$; $C_{i}$ : special solution, $\mu \mathrm{g} / \mathrm{m}^{3} ; \bar{c}$ : medium concentration, $\mu \mathrm{g} / \mathrm{m}^{3} ; C_{\max }$ : maximum concentration measured in the control room, $\mu \mathrm{g} / \mathrm{m}^{3}$; D: constant of integration, $\mu \mathrm{g} /\left(\mathrm{m}^{2} \mathrm{~s}\right)$; E: total emission, $\mathrm{kg}$; F: constant of integration, $\mu \mathrm{g} /\left(\mathrm{m}^{2} \mathrm{~s}\right) ; F_{c}$ : source term Janicke, $\mu \mathrm{g} /\left(\mathrm{m}^{2} \mathrm{~s}\right) ; \mathrm{H}$ : height of the measuring cross section, $\mathrm{m}$; $K, K_{B}$ : diffusion coefficient, $\mathrm{m}^{2} / \mathrm{s} ; \mathrm{L}_{\mathrm{x}}, \mathrm{L}_{\mathrm{y}}, \mathrm{L}_{\mathrm{z}}$ : geometric dimensions, $\mathrm{m} ; \dot{\mathrm{m}}_{\mathrm{g}}$ : total mass flow, $\mu \mathrm{g} /\left(\mathrm{m}^{2} \mathrm{~s}\right) ; \dot{\mathrm{m}}_{\mathrm{s}}$ : sedimentation stream, $\mu \mathrm{g} /\left(\mathrm{m}^{2} \mathrm{~s}\right) ; \dot{\mathrm{m}}_{\mathrm{d}}$ : deposition power, $\mu \mathrm{g} /\left(\mathrm{m}^{2} \mathrm{~s}\right) ; \dot{\mathrm{q}}$ : source term, $\mu \mathrm{g} /\left(\mathrm{m}^{2} \mathrm{~s}\right) ; \mathrm{r}$ : reciprocal transport speed, $1 /$ $(\mathrm{m} / \mathrm{s}) ; \mathrm{T}$ : deep ground, $\mathrm{m}$; t: time coordonate, $\mathrm{s} ; v_{d}$ : deposition velocity, $\mathrm{m} / \mathrm{s} ; v_{s}$ : sedimentation speed, $\mathrm{m} / \mathrm{s} ; \bar{v}_{d}$ : mean deposition rate, $\mathrm{m} / \mathrm{s} ; \bar{v}_{d}^{*}$ : approximation mean deposition rate, $\mathrm{m} / \mathrm{s} ; v_{i}$ : flow coordinates, $\mathrm{m} / \mathrm{s} ; \mathrm{x}_{\mathrm{i}}$ : spatial coordinates, $\mathrm{m}$; $z$ : coordinates, $m ; z_{0}$ : nearby singularity, $m ; z_{*}$ : coordinate ground, $m$.

\section{Authors' contributions}

The author read and approved the final manuscript.

\section{Authors' information}

Prof. Dr.-Ing. habil. Rainer Schenk, Ordinarius für Strömungsmechanik, i.R, Rosenberg 17, 06193,WETTIN-LÖBEJÜM, OT Wettin, Germany, ibswettin@web. de.

Korr. Mitglied des Spiegelgremiums zU CENT/TC 264/WG $43+44$ im VDI und DIN Normenausschuss KRdL. 
Mitglied der Arbeitsgruppe VDI RL 3790, Blatt 3, Emissionen von Gasen, Gerüchen und Stäuben aus diffusen Quellen im VDI und DIN - Normenausschuss KRdL.

1968 doctorate to Dr.-Ing. at the Technical University of Merseburg. 1968-1970 additional studies in the field of "Computational Fluid Dynamics" at the Academy of Sciences of the former USSR in Novosibirsk, Akademgorodok. 1970 Lecturer in Theoretical Fluid Mechanics at the Technical University of Merseburg. Since 1972 active in the field of modeling of the spread of air pollutants at the Technical University of Merseburg and member of the main research area air pollution control at the Academy of Sciences of the former GDR. 1978 Calculation of transboundary pollutant flows and international cooperation with the Meteorological Institute of Leningrad University and with the NILU Institute Oslo. 1979 Calculation of long-distance transport Europe. 1979 Development of a $24 \mathrm{~h}$ forecast model and application by the Meteorological Service of the former GDR. 1980 Habilitation and scientific work in the field of numerical fluid mechanics and modeling of the spread of air pollutants under the direction of full members of the Academies of Sciences of the former USSR and former GDR Akademik JANENKO, Novosibirsk, and OM ALBRING, Dresden. 1980 participation in the construction of a data center east. 1980 Head of Environmental Monitoring at the Center for Environmental Design Wittenberg. 1982 Lecturer and University Professor of Fluid Mechanics at the Technical University of Zittau. 1985 Model for the calculation of the spread of radionuclides. 1994 honorary professor at the Technical University of Dresden, IHI Zittau. 1996 Research project model for the calculation of the spread of traffic emissions on behalf of the Ministry of the Environment Saxony-Anhalt. 2005 Research project model for the calculation of the expansion of heavy gases and vapors on behalf of the Ministry of the Environment of Saxony-Anhalt. 2007 Research project Mobile Environmental Data AVIS on behalf of the Arbeitsgemeinschaft für industrielle Forschung Berlin. 2008 Research Project Instruments Pollutant Prediction on behalf of the Arbeitsgemeinschaft für industrielle Forschung Berlin. 2010 Model for the calculation of the spread of traffic emissions taking into account moving point sources. 2015 Software developments for the evaluation of meteorological measurement series and for the development of cause analyzes.

\section{Author details}

${ }^{1}$ Rosenberg 17, 06193 Wettin-Löbejün, Germany. ${ }^{2}$ Dresden University of Technology, International University Institute Zittau, Sachsen, Germany.

\section{Competing interests}

The Federal Environment Agency Germany will contradict and publish.

\section{Availability of data and materials}

Data and material are freely available.

\section{Consent for publication}

A publication of this work is approved.

\section{Ethics approval and consent to participate}

Permission to undergo this work by an ethics committee is granted.

\section{Funding}

There is an equity financing.

\section{Publisher's Note}

Springer Nature remains neutral with regard to jurisdictional claims in published maps and institutional affiliations.

Received: 7 March 2018 Accepted: 21 June 2018

Published online: 04 July 2018

\section{References}

Albring W (1961) Angewandte Strömungslehre. Akademie Verlag, Berlin

Axenfeld F, Janicke L, Münch J (1984) Entwicklung eines Modells zur Berechnung des Staubniederschlages. Umweltforschungsplan des Bundesministers des Innern Luftreinhaltung, Forschungsbericht 10402 562, Dornier System GmbH Friedrichshafen, Im Auftrag des Umweltbundesamtes
Berljand ME (1982) Moderne Probleme der atmosphärischen Diffusion und Verschmutzung der Atmosphäre. Akademie-Verlag, Berlin

Gradstein IS, Ruschik IM (1963) Tabellen von Integralen, Summen und Reihen sowie ihre Anwendungen. Physikalisch-mathematische Literatur, Staatsverlag, Moskau, p 1963

Janenko NN (1969) Die Zwischenrittmethode zur Lösung mehrdimensionaler Probleme der mathematischen Physik. Springer-Verlag, Berlin

Janicke L (2000) IBJparticle, Eine Implementierung des Ausbreitungsmodells Bericht IBB Janicke

Janicke (2001) Ausbreitungsmodell LASAT Referenzbuch zur Version 2.10, Dezember

Janicke (2002) AUSTAL2000, Programmbeschreibung, Dunum

Janicke U, Janicke L (2002) Entwicklung eines Modellgestützten Beurteilungssystems für den Anlagenbezogenen Immissionsschutz. IBJanicke

Naue G (1967) Einführung in die Strömungsmechanik. Reprocolor, Leipzig

Schenk R (1980) Numerische Behandlung instationärer Transportprobleme, Habilitation. TU Dresden, Dresden

Schenk R (2015a) AUSTAL2000 ist nicht validiert. Immissionsschutz 01.15, S. $10-21$

Schenk R (2015b). Replik auf den Beitrag „Erwiderung der Kritik von Schenk an AUSTAL2000 in Immissionsschutz 01/2015". Immissionsschutz 04.15, S. 189-191

Schenk R (2017) The pollutant spreading model AUSTAL2000 is not validated. Environ Ecol Res 5(1):45-58

Schlichting H (1964) Grenzschichtheorie. Verlag G. Braun, Karlsruhe

Simpson D, Benedictow A, Berge $H$, Bergström R, Emberson LD, Fagerli $H$, Flechard CR, Hayman GD, Gauss M, Jonson JE, Jenkin ME, Hyiri A, Richter C, Semeena VS, Tsyro S, Tuovinen JP, Valdebenito A, Wind P (2012) The EMEP MSC-W chemical transport model-technical description. Atmos Chem Phys 12:7825-7865

Truckenbrodt E (1989) Fluidmechanik. Springer, Berlin

Trukenmüller A (2016) Äquivalenz der Referenzlösungen von Schenk und Janicke. Abhandlung Umweltbundesamt Dessau-Rosslau, IBS Archiv, S. 1

Trukenmüller A (2017) Stellungnahmen Umweltbundesamt vom 10.02.2017 und 23.03.2017. Dessau-Rosslau, IBS Archiv, S. 1-15

Trukenmüller A, Bächlin W, Bahmann W, Förster A, Hartmann U, Hebbinghaus H, Janicke U, Müller WJ, Nielinger J, Petrich R, Schmonsees N, Strotkötter U, Wohlfahrt T, Wurzler (2015) Erwiderung der Kritik von Schenk an AUSTAL2000 in Immissionsschutz 01/2015. Immissionsschutz 03/2015, S. $114-126$

VDI 3945 Blatt3 (2000) Umweltmeteorologie-Atmosphärisches Ausbreitungsmodell_-Partikelmodell. Beuth Verlag, Berlin

VDI Kommission Reinhaltung der Luft (1988) Stadtklima und Luftreinhaltung. Springer, Berlin

Venkatram A, Pleim J (1999) The electrical analogy does not apply to modeling dry deposition of particles. Atmos Environ 33:3075-3076

\section{Submit your manuscript to a SpringerOpen ${ }^{\circ}$ journal and benefit from:}

- Convenient online submission

- Rigorous peer review

- Open access: articles freely available online

- High visibility within the field

- Retaining the copyright to your article

Submit your next manuscript at $>$ springeropen.com 